\title{
The Structure of Phenomenal Justification
}

\author{
Uriah Kriegel \\ Forthcoming in Australasian Journal of Philosophy
}

\begin{abstract}
An increasing number of epistemologists defend the notion that some perceptual experiences can immediately justify some beliefs and do so in virtue of (some of) their phenomenal properties. But this view, which we may call phenomenal dogmatism, is also the target of various objections. Here I want to consider an objection that may be put as follows: What is so special about perceptual phenomenology that only it can immediately justify beliefs, while other kinds of phenomenology - including quite similar ones - remain 'epistemically inert'? I will argue that to overcome this objection, the phenomenal dogmatist should incorporate into her view a general principle - I call it the 'experiential attitude/doxastic content link' principle - that essentially extends the view from the perceptual case to other phenomenal states.
\end{abstract}

Keywords: dogmatism, perceptual phenomenology, justification, content/attitude

Can a conscious experience justify you in believing something purely in virtue of what it is like for you to have that experience? Some philosophers think so, defending what I will call phenomenal dogmatism: 
(PD) For some experience E and belief B, (i) E provides immediate prima facie epistemic justification for B and (ii) E does so in virtue of (some of) E's phenomenal properties.

Here immediate justification for a belief B is justification that is independent of the subject's justification for any of her other beliefs; prima facie justification is justification that can be overturned or overridden by defeaters; and epistemic justification is (very roughly) justification for thinking that something is the case (i.e., for taking the world to be a certain way). ${ }^{1}$

Something like PD is defended by Pryor (2000), Huemer (2001), and following them many others. But PD is also the target of various criticisms. Some come from Bayesian probability theory, some from the psychology of cognitive penetration, some from broadly Sellarsian reflections on what it takes to justify, and some from other sources. Here I want to consider an objection that may be put as follows: What is so special about perceptual phenomenology that only it can immediately justify beliefs, while other kinds of phenomenology - including quite similar ones - remain 'epistemically inert'? This objection has been aired a number of times in the recent literature (e.g., Ghijsen 2014, Siegel and Silins 2015, Teng 2018). The reason I want to consider it is not that I think it is specially formidable, but because my response to it will lead to a deeper understanding of the general phenomenon of phenomenal justification - the very idea of justification in virtue of phenomenology.

\footnotetext{
${ }^{1}$ Moreover, we have in mind specifically propositional rather than doxastic justification justification that one has for believing regardless of whether one in fact believes.
} 


\section{Phenomenal Dogmatism; and an Initial Challenge}

One way to appreciate PD is by contrasting the doxastic stances it is epistemically rational for someone to take when they experience a certain phenomenology versus when they do not. Consider this vignette:

(Dark Room) You wake up from a groggy nap and find yourself in a pitch-dark room that feels unfamiliar. A warm voice startles you with a question: do you (a) believe that there is a chair in the room, (b) disbelieve that there is a chair in the room, or (c) suspend judgment about whether there is one. After you answer, the lights come on, and you have a vivid perceptual experience as of a chair right in front of you. The voice comes on again and asks whether now you (a) believe, (b) disbelieve, or (c) suspend judgment about there being a chair in the room.

Intuitively, the doxastic attitude it is most rational for you to take the first time around is to suspend judgment; but once the lights come on, it is more rational for you to believe. ${ }^{2}$ Choosing to believe while lying in unfamiliar pitch dark seems like epistemic irrational exuberance, but choosing to suspend judgment when experiencing a chair lying right there before your wide-open eyes seems like perverse cautiousness (McGrath 2013).

\footnotetext{
2 If spaces one woke up in unexpectedly were widely known to feature chairs, then background beliefs would make it rational for you to believe even in the darkness. But a more elaborate thought experiment could certainly make sure that the proposition up for belief, disbelief, or judgmentsuspension is one that obtains $50 \%$ of the time. Background beliefs then would make no difference.
} 
What explains the change in which stance is rational? A natural explanation is that first you experienced no chair phenomenology and then you did. One alternative explanation might be that once the lights came on, a mechanism of visual chair-detection, reliable in well-lit rooms, produced a certain perceptual state in you. It is not because of the phenomenology of this perceptual state, but because of its etiology, that it is now rational for you to believe that there is a chair in the room. Phenomenal dogmatists resist this alternative explanation, roughly on the following grounds (Smithies 2014). The intuition about a change in which attitude is rational does not disappear when we run Dark Room with an envatted phenomenal duplicate of you; yet your duplicate's chair-detection mechanism is entirely unreliable (failing as it does to lead to a preponderance of true beliefs).

Suppose, though, that between the two appearances of the warm voice, the lights do not come on, and consequently you have no perceptual experience as of a chair; but as it happens, you are visited by an extraordinarily vivid imaginative experience as of a chair before you. Intuitively, this would not justify a change in doxastic stance: after undergoing this imaginative experience, it is still most rational for you to suspend judgment on whether there is a chair before you. Thus having a vivid chair phenomenology is not sufficient to justify belief. Perhaps with the aid of an accompanying (justified) belief to the effect that your experience is perceptual rather than imaginative, your chairy phenomenology can justify believing that there is a chair before you. But the need for such a supporting belief would mean that the justification is no longer immediate, so it is not purely in virtue of your chair phenomenology that your chair belief would be justified. 
The phenomenal dogmatist has two options here. One is to reject the intuition that an imaginative experience could never immediately justify a perceptual belief. Perhaps some imaginative experiences do justify perceptual beliefs, notably if they have the same phenomenology as perceptual experiences or are mistaken for perceptual experiences (introspection is not infallible, after all!). If so, the phenomenal similarity of imaginative and perceptual experiences poses no problem to the notion that experiences can immediately justify purely in virtue of their phenomenology.

The other option is to say that imaginative experiences as of chairs never really have the very same phenomenology that perceptual experiences of chairs do: there are subtle but systematic phenomenal differences between perception and imagination, and something about the distinctive phenomenology of perceptual experience uniquely poises it to justify perceptual beliefs.

As we will see in $\S 2$, both Pryor and Huemer opt for the second option. Bracketing the issue of the ultimate plausibility of the two options, I will follow Pryor and Huemer in exploring the possibility of systematic phenomenal differences between perception and imagination. Again I do so mainly because it is this response that would lead us, I want to show, to a deeper understanding of the very phenomenon of phenomenal justification.

Importantly, there are two quite different versions of the idea that imaginative and perceptual experiences have systematically different phenomenologies; we may put them informally as follows: 
(R1) The chairy quality of imaginative chair phenomenology can never match the chairy quality of perceptual chair phenomenology; concentrate as hard as you might, you cannot conjure up an image of a chair quite as vivid, acute, and detailed as any average perceptual experience of a chair.

(R2) In addition to its chairy quality, a perceptual chair experience also has a subtle quality of perceptuality, and it is this that distinguishes it from imaginative chair experiences, which have rather a quality of imaginativeness.

R1 is in many respects the simpler option, but in fact both Pryor and Huemer go for R2. We will discuss their views in more detail in $§ 2$. But first it might be useful to consider some of the limitations of R1 that motivate pursuing R2.

First, even if an imaginative experience of a chair as vivid, acute, and detailed as a perceptual experience were not psychologically in the cards for us, it still seems metaphysically possible for such an experience to occur (to some sentient creature), and this is all the imagination objection appears to require. Secondly, a perfect match seems in fact nomologically possible. Visualize if you will a drawing of a chair. It should be possible for an unwitting illustrator to draw a chair such that seeing that drawing under the right circumstances would reproduce perfectly the phenomenology of your visualization (Byrne 2010: 17). Thirdly, actual cases of this sort are in fact common - they just tend to occur outside visual perception. Try to imagine a particularly wonderful smell of freshly brewed coffee. The coffee-ish quality of the olfactory image you just conjured up may well match for vivacity, detail, and acuteness the quality of my current olfactory perception as I appear to sniff in the distance an underwhelming cup of coffee. 
Relatedly, the notions of a vivid, acute, and detailed phenomenology are in truth far from straightforward. Suppose Sam, sitting in Singapore, imagines a deafeningly loud explosion right in the middle of her office; while Sasha, dining in Shanghai, hears a dim faraway explosion-ish sound. Which sound experience is more 'vivid, acute, and detailed' (cf. Sartre 1936: 84)? It depends of course on what all these words mean; the point is that the phenomenal dogmatist cannot simply brandish those terms and consider the challenge from imagination neutralized. As soon as we step outside the visual domain (and perhaps the tactile as well), the phenomenal characteristics vaguely intimated by these terms are much more commonly shared across perceptual and imaginative experiences. Yet it would be very strange for a phenomenal dogmatist to claim that visual and tactile perceptions (say) provide immediate justification while auditory, olfactory, and gustatory perceptions do not.

Perhaps for such reasons, Pryor and Huemer pursue R2 (see §2). Rather than claim that the chairy quality of chair-perceptions differs from that of chair-imaginings, they claim that perceptual chair experiences have a perception-ish quality that differs from imaginative chair experiences' imagination-ish quality. The challenge, of course, is to explain (a) what these perception-ish and imagination-ish qualities are supposed to be, and (b) how the phenomenological difference between them is supposed to ground an epistemic difference. In the next section, we attend to (a); thereafter we will turn to (b).

\section{Perception, Imagination, and the Content/Attitude Distinction}


One phenomenal difference between perceiving and imagining as such (i.e., independently of the content perceived or imagined) is this: perceiving $x$ is typically will-resistant whereas imagining $x$ is not. Some imaginings comes to us unbidden, and some are obsessivecompulsive, in a way that makes them at least partially non-will-resistant; and some perceivings-as are more agentive and willful - think of seeing a sheep in the clouds or a rabbit on the moon's surface. Still, the correlation between the perception/imagination and will-resistant/non-will-resistant distinctions is real and potentially epistemically significant. Yet neither Pryor nor Huemer appeals to it in explaining the difference in epistemic oomph between perceiving and imagining. We will return to why toward the end of this section.

According to Pryor and Huemer, what distinguishes perceptual from imaginative experiences is the former's phenomenal 'force' or 'forcefulness':

[I]t's not the irresistibility of our perceptual beliefs ... which explains why our [perceptual] experiences give us the immediate justification they do. Rather, it's the peculiar "phenomenal force" or way our experiences have of presenting propositions to us. Our experiences represent propositions in such a way that it "feels as if" we could tell that those propositions are true... [T]his "feeling" is part of what distinguishes the attitude of [perceptually] experiencing that $p$ from other propositional attitudes, like belief and visual imagination. (Pryor 2000: 547 fn37)

Even if you have a very vivid, very detailed imagination, or you have very poor eyesight, you still would never confuse seeing a tomato with imagining one. The reason lies in what I call the "forcefulness" of perceptual experiences: perceptual experiences represent their contents as actualized; states of merely imagining do not. When you have a visual experience 
of a tomato, it thereby seems to you as if a tomato is actually present, then and there. When you merely imagine a tomato, it does not thereby seem to you as if a tomato is actually present. (Huemer 2001: 77)

Pryor's notion of phenomenal force and Huemer's notion of forcefulness are very similar not just in name but in substance. Both take the relevant feature to distinguish the phenomenology of perceiving from that of imagining, and both take it to be external to the content of experience: it is not a matter of the contents perceived or imagined, but of the very 'attitude' - perceiving vs. imagining - taken toward those contents. There is a way perceptual experience relates representationally to its content that is different, on Pryor's and Huemer's views, from the way imaginative experience relates representationally to its content. And this difference in attitude or representational relation to content makes a phenomenal difference.

Moreover, both take the experiential attitude characteristic of perception, but not of imagination, to be an assertoric attitude, committing to the world being a certain way, namely the way specified in the content. When you have a perceptual experience of a blue chair, your experience takes a stand on how the world really is: it 'tells you' that the world contains a blue chair right there. This is different from the experiential attitude involved in imagination: when you imagine a blue chair, the imaginative experience does not 'tell you' to take the world to be the way the experience's content specifies.

In this respect perceiving differs from imagining somewhat as believing that $p$ differs from wondering whether $p$. The content in both latter cases is $\langle p\rangle$, but when the attitude we take toward $\langle p>$ is the belief attitude, we commit ourselves to the world really being 
such that $p$; whereas when the attitude we take toward $<p>$ is that of wondering, we do not. This is, presumably, because of the nature of the attitudes taken. The belief attitude in some sense frames $p$ as being the case; the wondering attitude does not. Similarly, a perceptual experience, in Pryor's and Huemer's conception, frames the subject's surroundings as really being the way the experience's content specifies. An imaginative experience as of a qualitatively indistinguishable scene is unlike that - it does not frame the imagined scene as characterizing the way the subject's surroundings really are.

How does an imaginative experience frame its content? According to Yablo (1993), imagining a blue chair frames a blue chair as possible. Sartre (1940: 183) thought it frames the blue chair as absent or 'not there.' Other views are possible as well. What matters for our purposes is just this: even if a perceptual and an imaginative experience of a blue chair had the exact same content, their overall phenomenology would still be different due to employing different experiential attitudes toward that content.

One important difference between Pryor's and Huemer's views, at least as presented in the passages quoted above, is that Pryor speaks of an attitude that tells us to take the content as true, whereas Huemer speaks of an attitude that tells us to take the content 'as actualized' or 'as actually present then and there.' I will work here with Huemer's characterization, for the following reason. Speaking of presenting the content 'as true' implies that perceptual content is the kind of thing that can be true or false, which suggests a propositional conception of perceptual content. To my mind, however, there is no need for phenomenal dogmatism to commit to perceptual content being propositional, objectual, or sometimes propositional and sometimes objectual. (On objectual attitudes, see Forbes 
2000.) A paradigmatic example is love: what proposition $p$ might be such that loving for my son would amount to my loving that $p$ ?) Indeed, to me it seems more intuitive that perceptual experience is at least sometimes objectual. Ordinary language certainly offers us not only the 'S perceives that $p$ ' construction, but also 'S perceives $x$. ' And intuitively, when an Albanian shepherd atop a scraggly mountain takes in the sun setting over the Adriatic, his many goats amiably milling about, it is odd to say that what is thereby present to his mind is a proposition - even if what is present to his mind is profitably modeled by a proposition. Now, when content is objectual we cannot speak of it being true or false. If S has an experience of a yellow lemon, it seems like a category mistake to say that the yellow lemon is true. But it would be perfectly legitimate to say that a yellow lemon is actually present then and there.

To summarize the point: because I find it more natural to think of perceptual experience as being (sometimes) objectual rather than propositional, I follow Huemer in taking the perceptual attitude to frame its object as actual, or (better) actually present here and now. To capture the fact that this actual-presence is a dimension of perception's attitude rather than content, I will say that a perceptual experience of a blue chair does not quite present a blue-chair-as-actual, but rather presents-as-actual a blue chair; or that it represents-as-actually-present-here-and-now the blue chair, rather than represents a bluechair-as-actually-present-here-and-now. ${ }^{3}$ These descriptors are meant to characterize the distinctive manner by which perception relates representationally to its content, somewhat as truth characterizes the specific manner belief that $p$ relates representationally to $<p>$ :

\footnotetext{
${ }^{3}$ I will use 'present' and 'represent' interchangeably, though it is certainly possible to leverage their differing connotations to do some substantive work.
} 
when we say that belief that $p$ frames $<p>$ as true, we do not mean that the belief's content is $<p$ is true>; no, the content is simply $<p>$, and the belief represents-as-true that content. Similarly, a perceptual experience of a yellow lemon represents-as-actually-present-hereand-now the content <yellow lemon>.

My suggestion is that this representing-as-actual(ly-present-here-and-now) is what the phenomenal force(fulness) of perceptual experiences amounts to. Imaginative experiences of qualitatively indistinguishable scenes lack this feature. On a Yablovian view, an imaginative experience of a blue chair represent-as-possible a blue chair. Representingas-actual and representing-as-possible are two different manners of representing the same content. On a Sartrean view, the attitude characteristic of imagining is rather representingas-absent, or representing-as-absent-here-and-now, which contrasts more clearly with representing-as-present-here-and-now.

These hyphenated expressions are of course purely technocratic. The point is just that for Pryor and Huemer, even when the content-based phenomenal features of imaginative and perceptual experiences match perfectly, they still differ phenomenally in virtue of an 'attitudinal' difference between them: the quality of representing-as-actual, or representing-as-actually-present-here-and-now, constitutes the quality of perceptuality mentioned at the end of $\S 1$; while representing-as-possible, or representing-as-absenthere-and-now, or whatever is ultimately the right attitudinal characterization here, constitutes the quality of imaginativeness.

Setting aside the specifics of Pryor's and Huemer's accounts, the basic idea here is to distinguish perceptual from imaginative phenomenology in terms of these experiences' 
distinctive attitudes, not the contents perceived/imagined. Why do Pryor and Huemer prefer this kind of attitudinal account over a content account? Presumably, because they think that nothing rules out the very same content being perceived by $S$ and imagined by $S^{*}$ - for all the reasons cited at the of $\S 1$.

But why prefer an attitudinal account over an account in terms of will-resistance (characteristic of perception but not imagination)? ${ }^{4}$ Three potential reasons may be cited. First, as noted some perceptions involve a willful element (e.g., seeing a horse in the clouds, seeing a figure as duck rather than rabbit); whereas the attitudinal characterization of perceptuality is supposed to capture its very nature - what makes perceptual experience the mental state type it is - and should thus be exceptionless. Secondly, even if perceptual experience were always will-resistant, this might not always show up in the phenomenology: it is one thing for perception to be will-resistant, another for it to feel will-resistant. Thirdly, any phenomenal difference in will-resistance is plausibly explained by the attitudinal differences between perception and imagination. Compare: you can (typically) wonder whether $p$ at will, but not believe that $p$ at will, but this seems to flow from, rather than underlie, the difference between what it is to wonder versus believe. Because belief is concerned with what is in fact the case, and what is the case is not up to us, we cannot typically believe at will. By the same token, I suggest, because perception is concerned with what is actually present hic et nunc, which is not up to us, we cannot typically have a perceptual experience as of $x$ at will. Thus will-resistance is plausibly a symptom of the attitudinal nature of perceptual experience (and ditto for non-resistance and imaginative experience).

${ }^{4}$ Thanks to Giulia Martina and an anonymous AJP referee for pressing me on this point 


\section{The Uniqueness Challenge}

Some writers have contested the notion that phenomenal forceful(ness) cleanly separates perceptual from imaginative experiences, arguing that some perceptual experiences lack it (Ghijsen 2014) or that some imaginative ones have it (Teng 2018). But these arguments often rely on very specific interpretations of the so-called Perky Effect (Perky 1910): when subjects facing a screen are asked to imagine a banana, while unbeknownst to them an ever-so-dim image of a banana is surreptitiously projected on the screen, they report having imagined a banana, not having perceived a banana. Many interpretations of this are possible. The one anti-dogmatists rely on is that Perky subjects have perceptual experiences which they confuse for imaginings. Such confusion is only possible, they claim, if perceptual experiences do not have a phenomenal force(fulness) that imaginative experiences lack. However, the experimental results proper are consistent with many other interpretations. It is worth noting, first of all, that Perky included very little of his subjects' actual reports, and what he included is extremely ambiguous (see for yourself - Perky 1910: 432). In any event, it is entirely consistent with Perky's data that his subjects had both perceptual and imaginative banana experiences, the latter perhaps primed by the former.

Regardless of Perky, though, surely subjects sometimes mistake a perceptual for an imaginative experience. This might be taken to tell against the idea of an attitudinal phenomenology of perceptuality: if there were such a phenomenology, it might be argued, introspective mistakes of this sort would be impossible. 
In this form, however, the objection presupposes that introspection - at least of attitude-based phenomenology - is infallible. But it is quite implausible that introspection is infallible, and there is no special reason to think attitude-based phenomenology should be more resistant to introspective misrepresentation than content-based phenomenology. Observe, in this respect, that PD, as formulated at the opening, in no way implies that subjects have infallible access to their phenomenology. This is just as it should be: for phenomenal dogmatism to wed itself to introspective infallibility would be 'dialectically suicidal,' given the low acceptance of introspective infallibility among contemporary epistemologists. The phenomenal dogmatist does well to allow that, just as perception occasionally misrepresents the subject's environment, and introspection the subject's content-based phenomenology, so introspective misrepresentations of attitude-based phenomenology should occasionally occur - including misrepresentations of instances of the phenomenology of perceptuality.

The possibility of such introspective misrepresentation does force a dilemma on the phenomenal dogmatist: she must decide whether it is (a) the phenomenology subjects actually have or (b) the phenomenology subjects introspectively take themselves to have, that provides the kind of immediate justification she has in mind. As PD reads, it is (a) that is the case. We could, of course, formulate a thesis that makes the choice of (b) instead. But I think there is good reason to stick with (a). Even if introspection sometimes mistakes a perceptual for an imaginative experience, and on other occasions gets things right, most of the time there is no introspective uptake at all - we just 'live through' our stream of consciousness, without 'stepping back' to introspectively assess it. In those circumstances, (b) would deprive the subject of justification. However, the intuitive motivation for 
phenomenal dogmatism, as seen e.g. in (Dark Room), is still present. So what generates the antecedent motivation for phenomenal dogmatism appears to track (a), not (b).

If we stick with (a) - hence with PD as is - it means that subjects who have a perceptual experience of a blue chair, but introspectively mistake it for an imaginative experience, do have immediate justification for believing that there is a blue chair before them - though they are unaware of having this justification; and subjects who introspectively mistake an imaginative for a perceptual experience do not have justification for the relevant belief, even if they think they do. This should not be surprising: a view that grounds a certain type of justification in phenomenology, and also allows for introspective fallibility regarding phenomenology, should be expected to allow for introspective fallibility regarding justification. ${ }^{5}$

Even if we grant that perception and imagination differ in attitude-level phenomenology, there are difficult questions surrounding the special epistemic oomph claimed specifically for the perceptual attitude. What is it about the 'perception-ish' phenomenology that endows it with epistemic force that the 'imagination-ish' phenomenology lacks? Phenomenal dogmatists must explain why perceptual experience's distinctive attitudinal character uniquely poises it to provide the immediate justification that it provides.

${ }^{5}$ On certain ways of drawing the internalism/externalism divide in epistemology, this consequence might deprive phenomenal dogmatism of its status as an internalist view, and that would be surprising. However, insofar as the only way for phenomenal dogmatism to block this consequence is to commit to introspective infallibility (at least regarding attitude-based phenomenology), I think the wiser choice is to regard the internalist status as negotiable and dependent in part of one's conception of the internalism/externalism divide. 
One way to bring out the difficulty is to note that recollection - what cognitive psychologists call 'episodic memory' - also represents-as-actual its object. Can you recall the last time you saw a tiger at the zoo? When you recall the scene, how things looked and how you felt, you are having a recollection experience - an episodic memory. This kind of recollection experience, like perceptual experience, represents-as-actual its content. (There are also differences, as we will see momentarily, but what I want to highlight now is an attitudinal similarity between the two.) We can see this by contrasting recollecting and imagining. Suppose Sam proposes to Sasha, only to be awkwardly spurned. A week later, Sam recalls the scene in anguish, especially the moment Sasha said no. But a week earlier, Sam imagined a scene that happened to be qualitatively indistinguishable, except that Sasha said yes. Up to the 'yes' or 'no' moment, the two experiential episodes have the same content-level phenomenology, representing the same sequence of events, in the same settings, with the same vivacity, etc. Still they differ in this respect: the recollection frames the events as having really happened, whereas the imagination does not. Thus recollecting represents-as-actual its content.

This is not to deny, of course, an attitude-level phenomenal difference between perception and recollection. Recall Huemer's more involved gloss on forcefulness: it frames the object as actually present here and now. A recollection experience need not frame its object as here and certainly does not frame it as now. On the contrary, according to some 
philosophers, it is distinctive of recalling that it frames its object as in the past - i.e., that it represents-as-past its object (Kriegel 2015a: 409). ${ }^{6}$

We might say that the perceptual and recollective attitudes resemble in their 'ontological profile,' along which they differ from the imaginative attitude: the latter represents-as-possible where the former represent-as-actual. At the same time, perceptual and recollective experiences differ in their 'temporal profile,' the former representing-asnow, the latter representing-as-past. It would seem that just as there are dis/similarities between experiences along various dimensions of content, there are also dis/similarities between them along different dimensions of attitude.

The question is why should the specific profile of the perceptual attitude uniquely poise perception to justify immediately. What is it about a perceptual experience of a blue chair that allows only it to provide immediate justification for a blue-chair belief? Sure, perceptual experience exhibits a distinctive overall attitudinal profile that no other type of experience exhibits. But different aspects or dimensions of this profile it may share with some other types of experience, which sport their own distinctive overall attitudinal profiles. What is so special about the perceptual profile that invests perception with the singular epistemic distinction of enabling immediate justification? Call this the Uniqueness Challenge for phenomenal dogmatism.

6 I am assuming here that the pastness information is 'attitudinally encoded' in recollection the way the 'now-ness' information is in perception. One recalls seeing a tiger, and the seeing was in fact in the past, but it is not part of what one recalls that, ah yes, the experience occurred in the past. For a fuller argument for this, see Kriegel 2015a. 
I want to be clear on what this challenge is - and what it is not. It is not the challenge of explaining how immediate justification is possible at all, nor why perceptual experience can provide it. All this is taken for granted by the time we are joining the dialectic. What the Uniqueness Challenge asks of us is to explain why, given that perceptual phenomenology can provide immediate justification, other types of phenomenology, including quite similar ones, cannot. That is, it is the challenge of explaining why perceptual phenomenology should be unique in having epistemic oomph.

\section{Extending Phenomenal Dogmatism}

The phenomenal dogmatist's best response, I want to suggest, is to say that there is nothing epistemically special about perceptual experience. Instead, perceptual, recollective, imaginative, and perhaps other types of experience immediately justify each its own kind of belief. It is true that only perceptual experience of the chair immediately justifies the belief that there is a chair before me. But recollective experience immediately justifies the belief that there was a chair before me and imaginative experience immediately justifies the belief that there could be a chair before me. Recollections justify beliefs about the past ('historical beliefs') and imaginations beliefs about possibilities ('modal beliefs') in the same way perceptions justify beliefs about one's surroundings ('perceptual beliefs'). ${ }^{7}$

\footnotetext{
7 I indulge here the Yablovian view of imagination. If you prefer a different view, the point would be restated in terms of that other view (e.g., if imagination frames its content as absent, then the claim would be that imaginative experiences immediately justify absence beliefs).
} 
In each case, the phenomenal dogmatist should claim, there are specific kinds of belief that are eligible for immediate justification by experience. Which beliefs are eligible in which case is determined by the attitude-level features employed in each type of experience. It is because the recollection experience represents-as-past the chair that it immediately justifies a past-chair belief; it is because perceptual experience represents-aspresent that it justifies a present-chair belief (whether we read 'present' as a synonym of 'now' or as the antonym of 'absent'); and it is because imagination represents-as-possible that it immediately justifies a possible-chair belief.

The above remarks suggest a general way in which an experience E, perceptual or otherwise, may immediately justify a belief B: namely, when B's content is $<x$ is $\mathrm{F}>$ and $\mathrm{E}$ represents-as-F the content $\langle x\rangle$. Thus, if one experience represents-as-past $\langle x\rangle$, and another represents-as-now $\langle X\rangle$, then the first experience immediately justifies a belief with the content $<x$ is past $>$, while the second immediately justifies a belief with the content $<x$ is now>. The idea is that there is a link between experiential attitude and doxastic content that underwrites experiences' ability to immediately justify just the kinds of belief they do. This link ensures that for every experiential attitude A there is a corresponding propositional content $\mathrm{C}$, such that believing $\mathrm{C}$ would be immediately (prima facie) justified by any experience that exhibits A toward the right content.

Now, the proposed link between experiential attitude and doxastic content supports phenomenal dogmatism only where representing-as- $\mathrm{F}$ is a phenomenal property. Otherwise, all the link supports is dogmatism more generically, i.e. the idea that experience immediately justifies some beliefs. To get that an experience immediately justifies beliefs in 
virtue of phenomenology, its representing-as-F must show up in the phenomenology. As we have seen, both Pryor and Huemer do take representing-as-F to be a phenomenal property in the perceptual case. But as we extend phenomenal dogmatism beyond perception, we must keep in mind that the extension is restricted to those experiences that phenomenally represent-as-F their contents. It is of course possible to hold that no attitudinal property is phenomenal (as 'pure representationalists' do). But many philosophers of mind do take attitude to at least sometimes show up in the phenomenology (e.g., Cohen 1992, Peacocke 1998, Horgan and Tienson 2002, Kriegel 2015b, Mitchell 2020).

With all this in mind, we may formulate the general experiential attitude/doxastic content link as follows:

(LINK) When a subject $\mathrm{S}$ undergoes an experience that phenomenally represents-as-F some content $\langle x\rangle, \mathrm{S}$ thereby has immediate prima facie epistemic justification for a belief with the content $<x$ is $\mathrm{F}>$.

Note that LiNK takes no stand on which experiences (if any!) phenomenally represent-as-F some content. For all LinK says, immediate justification may still turn out to be the prerogative of perceptual experience. Nonetheless, LiNK makes possible an extension of phenomenal dogmatism to a whole range of non-perceptual experiences - and that is how it helps overcome the Uniqueness Challenge. ${ }^{8}$

${ }^{8}$ If it turns out that perceptual experiences are the only experiences that represent-as- $F$ phenomenally, then perceptual phenomenology would turn out to have a singular epistemic oomph after all. Even then, though, LINK would offer us a reason why this should be so, thus meeting the Uniqueness Challenge sin a different way. 
It may be useful to compare LiNK with Huemer's 'phenomenal conservatism,' which also extends immediate justification beyond perception - to all states of 'seeming,' including recollective, intellectual, and introspective seemings. Huemer (2001: 99) formulates phenomenal conservatism thus:

(PC) If it seems to $S$ that $p$, then $S$ thereby has at least prima facie justification for believing that $p$.

Some differences between PC and LINK are superficial. Thus, PC is framed in terms of seemings, LinK in terms of experiences; but Huemer (2013 §2d) does hold that all seemings are experiences. Other differences, however, go deeper. In particular, note that in PC the contents of the justifying experience and the belief being justified are identical; whereas in LINK they are different, as some of the information showing up in the content of the belief is encoded instead in the experience's attitude. This seems to me to hold a double advantage for LINK.

First, LINK allows experiences to have objectual contents, whereas PC is forced to construe them as propositional, since the content of the belief being justified will always be propositional. It is not clear why - by what right, so to speak - an epistemological thesis should prejudge an open issue in the philosophy of mind.

Secondly, PC faces a dilemma regarding where to fit the actually-present-here-andnow information. If the experience and belief have the same content, the actually-presenthere-and-now element must be either (a) present in the content of both or (b) absent from the content of both. But both options are highly problematic. Option (a) implies that in an 
olfactory experience of freshly brewed coffee now-ness is being smelled the way coffee is smelled. It requires actuality to be a visible or audible quality the way colors and sounds are. Meanwhile, option (b) assigns the wrong truth conditions to the belief being justified. What seems to be immediately justified by a perceptual experience of a blue chair is a belief with the content <a blue chair is actually present here and now>, not a belief with a content like <a blue chair exists $>$. For the latter could be made true by a blue chair on the moon, and it is not a belief that could be made true by lunar chairs that your earthly perceptual experience justifies immediately. Relatedly, the belief that a blue chair exists is not a perceptual belief. Perceptual beliefs are precisely beliefs about the here and now. But presumably it is only perceptual beliefs that perceptual experiences can justify immediately. Thus both (a) inserting the actually-present-here-and-now element into the experiential content and (b) leaving that element out of the belief content lead to serious difficulties. LINK avoids these difficulties by keeping that information out of the experiential content but in the belief content. This is why it insists the two contents are different.

It may be objected that content identity is called for here, since the belief being justified can be formed by 'taking at face value' the corresponding experience. But the view that the content of the experience must be identical to the content of the belief faces extraordinary difficulties in handling certain problem cases (Silins 2011 §3). Anyway, 'taking at face value' is an impressionistic expression that can be understood in more than one way. The understanding suggested by LINK is this: to take an experience at face value is to form, on the basis of that experience, a belief that conveys the same information, but where some information encoded in the experience's attitude is carried explicitly in the belief's content. It is to perform a cognitive act that effects a certain informational 
reorganization, whereby some information 'migrates' from attitude to content (cf. Recanati 2007 Part 2).

\section{Three Versions}

What I am recommending to the phenomenal dogmatist is conjoining LiNK to PD, thus avoiding the charge of arbitrarily singling out perception for special epistemic significance. It is worth distinguishing, however, three versions of this kind of LiNK-enriched PD.

Consider that many philosophers hold that beliefs themselves can be conscious experiences, exemplifying 'proprietary cognitive phenomenology.' Suppose that part of what it is for conscious beliefs to constitute cognitive experiences is for them to (phenomenally) represent-as-true their contents (see Cohen 1992: 11, Kriegel 2015b: 656). Then by LinK's lights, a conscious belief/cognitive experience with the content $<p>$ should provide immediate justification for a belief with the content $<p$ is true $>$. But this is highly counterintuitive. Suppose that S's conscious belief that $p$ is completely unjustified, the result of wishful thinking and superstition entirely. Then presumably S's belief that $p$ does not justify $\mathrm{S}$ in believing $<p$ is true $>$. But even if a conscious belief that $p$ is justified, say because correctly deduced from justified beliefs that $q$ and that if $q$ then $p$, one's

justification for believing $<p$ is true $>$ would depend in part on the justification for believing $<q>$ and $<$ if $q$ then $p>-$ and thus would not be immediate justification.

There are three possible responses to this, each defining a different version of LinKenriched phenomenal dogmatism. The first is to deny the existence of cognitive 
phenomenology, or at least the kind of attitudinal cognitive phenomenology that could plug into LiNK. More generally, the strategy here is to reject any attitudinal phenomenology whose existence would produce counterintuitive results when plugged into LiNK.

The second option is to bite the bullet and accept that a cognitive experience that phenomenally represents-as-true $<p>$ provides immediate justification for believing that $p$ is true, while insisting that this justification is merely prima facie, defeasible justification. With a cognitive experience produced by wishful thinking and superstition, its problematic etiology constitutes a(n undercutting) defeater of the very real but defeasible justification that the cognitive experience provides for believing $<p$ is true $>$. It is admittedly unintuitive that simply being visited by a certain cognitive phenomenology could justify one in believing that $p$ is true. But it is after all the starting point of phenomenal dogmatism that simply having a certain kind of experience generates justification (a starting point which, recall, lies dialectically upstream from this paper's concerns). Since a phenomenal dogmatist accepts that being visited by a perceptual phenomenology that represents-aspresent $<x>$ generates prima facie, defeasible justification for believing $<x$ is present $>$, she should not feel overly embarrassed by the notion that being visited by a cognitive phenomenology that represents-as-true $<p>$ generates prima facie, defeasible justification for believing $<p$ is true $>$. Whether the belief is ultima facie, all-things-considered justified would depend also on various other factors, including the epistemic credentials of the cognitive experience that prima facie justifies it.

A third option is to require that whenever an experience immediately justifies a belief, it must be able to do so independently of anything justifying $i t$. For otherwise the 
justification for the belief would not come entirely from this experience, but partly from whatever justifies it. Accordingly, LINK must be restricted to experiences that do not need to be justified by anything else. Contemporary phenomenal dogmatists often hold that perceptual experiences are not assessable for justification in the first place (Pryor 2005: 210). In some versions of classical foundationalism, certain experiences were claimed to be somehow self-justifying. Either way, such experiences would be 'justification-autonomous': they would not need to be justified by anything outside themselves, so to speak. The suggestion under consideration is to reformulate LiNK so it applies only to justificationautonomous experiences. ${ }^{9}$

It is not our purpose here to take a stand on which option is best - they all constitute versions of PD that meet the Uniqueness Challenge. Personally, I like the first version least: tailoring one's phenomenology to fit one's epistemology seems like the wrong direction of theorizing. And I find myself slightly more sympathetic to the second version than the third, as it underwrites a more unified account of phenomenal justification as such. But I proffer these here as autobiographical remarks.

\section{Global Phenomenal Dogmatism}

Call the conjunction of PD and LINK global phenomenal dogmatism (GPD). I have argued that GPD meets the Uniqueness Challenge: given LINK, perception is not arbitrarily singled out

\footnotetext{
${ }^{9}$ The restricted principle might read as follows: If $S$ undergoes an experience that (i) phenomenally represents-as-F some content $\langle x\rangle$ and (ii) is justification-autonomous, then $\mathrm{S}$ has immediate prima facie epistemic justification for a belief with the content $<x$ is $\mathrm{F}>$.
} 
for unparalleled epistemic significance. On the contrary, every experience that employs a distinctive attitude-level phenomenology, whereby it phenomenally represents-as-F some content, immediately justifies a corresponding kind of belief.

Dogmatists often claim that the best way to motivate dogmatism is to simply reflect on everyday examples (Pryor 2000: 206). If someone asks 'How do you know Charles is in the room? What makes you so sure?,' the answer 'I am looking right at him!' would not be out of place. Intuitively, having a perceptual experience of Charles is about as good a reason as anyone can reasonably expect for believing that Charles is present. But notice, now, that if someone asks 'How do you know Chalmers gave the colloquium talk yesterday? What makes you so sure?,' the answer 'I remember it very clearly!' is just as natural. And if you ask yourself whether it would be possible to fit the desk through the door, it is natural to imagine trying to fit it through. If your imagination presents it as fitting through comfortably, then intuitively you are justified in believing that it is possible to get the desk through the door. Thus extending dogmatism beyond the perceptual domain flows nicely with the intuitive motivation for perceptual dogmatism..$^{10}$

In this picture, there is an elegant division of epistemic labor between experience's content and attitude. The attitude selects the kind of belief that is eligible for phenomenal justification. The experience's content then determines which belief of the relevant kind would in fact be justified by the experience. It is because the perceptual experience of a blue chair is a perceptual experience (rather than, say, a recollective experience) that the kind of beliefs it can immediately justify are perceptual (rather than historical); but it is because it

10 Thanks to Anna Giustina for pointing this out to me. 
is an experience of a blue chair (rather than, say, of a green table) that the specific perceptual belief it immediately justifies is a blue-chair (rather than green-table) belief. Likewise, it is because imagining a flying pig represents a flying pig (content aspect) that the specific modal belief it justifies is that a flying pig is possible; but it is because it represents-as-possible (attitude aspect) that the kind of belief it justifies is a modal belief.

Global phenomenal dogmatism thus has several appealing features. It neutralizes concerns about the arbitrarily special status of perceptual phenomenology. It is motivated by the same kind of reflection on everyday cases that motivated perceptual dogmatism originally. It explains why attitude plays an important epistemic role in phenomenal justification. It makes phenomenal dogmatism consistent with perceptual experiences being sometimes objectual rather than propositional. And it offers an elegantly unified and principled understanding of phenomenal justification in general, as grounded in a single structural principle linking experiential attitude and doxastic content - LINK.

A last virtue worth noting is that LINK offers us a concrete way to move forward in various recent debates about the extent of immediate justification. Consider for example the idea, increasingly prominent in the philosophy of emotion, that emotional experiences justify evaluative beliefs in somewhat the same way perceptual experiences justify perceptual beliefs (Döring 2007). On this view, my fear of the loose snake provides me with immediate (prima facie) justification for believing that the snake is dangerous to me, my indignation at the plight of the Kurds gives me immediate justification for believing that the plight of the Kurds is unjust, and so on. How should we evaluate this claim? Against the background of LINK, it would have to be the case that emotional experiences feature the 
right attitude-level phenomenology. ${ }^{11}$ If, for instance, fear experiences phenomenally represent-as-dangerous their objects (e.g., snakes), then by LinK's lights, fear experiences provide immediate justification for danger beliefs; if indignation phenomenally representsas-unjust its object, then indignation provides immediate justification for injustice beliefs; and so on.

Similar debates surround intuition experiences (whether they immediately justify certain a priori beliefs), introspective experiences (whether they immediately justify certain psychological beliefs), etc. (Huemer 2007, Chudnoff 2012). If LINK is right, the way to evaluate such claims is to consider whether intuitional and/or introspective experiences have the right attitude-level phenomenology. Thus LinK offers us a way to move forward the discussion in a whole range of important debates.

In conclusion, there is much to recommend incorporating LINK into phenomenal dogmatism. What I mean by this is mostly this: there are reasons for the phenomenal dogmatist to adopt LiNK. Anti-dogmatists are not going to warm up to dogmatism just because it is willing to go global; and if they oppose dogmatism because of Bayesian, Sellarsian, or cognitive-penetration-type worries, nothing about the incorporation of LINK would speak to their concerns. However, those who find some antecedent merit in phenomenal dogmatism, but worry about an inexplicably special status granted to perceptual phenomenology in it, should find a LinK-enriched dogmatism appealing. At the very least, the resulting global phenomenal dogmatism offers an elegantly unified account

\footnotetext{
${ }^{11}$ Note, though, that if one restricts LINK to justification-autonomous experiences, it would also have to be the case that emotional experiences are justification-autonomous.
} 
of the epistemic connection between experience and belief, as grounded in a single underlying structural principle linking experiential attitude and doxastic content. ${ }^{12}$

\section{References}

- Byrne, A. 2010. 'Recollection, Perception, Imagination.' Philosophical Studies 148: 15-26.

- Chudnoff, E. 2012. 'Presentational Phenomenology.' In S. Miguens and G. Preyer (eds.), Consciousness and Subjectivity. Frankfurt: Ontos Verlag.

- Cohen, L.J. 1992. An Essay on Belief and Acceptance. Oxford: Clarendon.

- Döring, S.A. 2007. 'Seeing What to Do: Affective Perception and Rational Motivation.' Dialectica 61: 363-394.

- Forbes, G. 2000. 'Objectual Attitudes.' Linguistics and Philosophy 23: 141-183.

- Ghijsen, H. 2014. 'Phenomenalist Dogmatist Experientialism and the Distinctiveness Problem.' Synthese 191: 1549-1566.

- Horgan, T. and J. Tienson 2002. 'The Intentionality of Phenomenology and the Phenomenology of Intentionality.' In D.J. Chalmers (ed.), Philosophy of Mind. New York: OUP.

- Huemer, M. 2001. Skepticism and the veil of perception. Lanham, MD: Rowman and Littlefield.

\footnotetext{
12 This work was supported by a Friedrich Bessel Research Award from Germany's Alexander von Humboldt Foundation. For comments on previous drafts, I am grateful to Juan Comesaña, Anna Giustina, Mike Huemer, Andrew Lee, Tricia Magalotti, Giulia Martina, Jim Pryor, Charles Siewert, Declan Smithies, and two anonymous referees for AJP. I have benefited from presenting the paper at the LOGOS research group, Rice University, the University of Hamburg, and at an online conference. I am grateful to the audiences there, in particular Mustafa Aghahosseini, Aarón Álvarez González, Filippo Contesi, Arnaud Dewalque, Manolo Garcia-Carpintero, Anthony Hatzimoysis, Thomas Kroedel, Martine Nida-Rümelin, Daniel Pinto, Elisabetta Sacchi, Reuben Sass, Anna Strasser, Patricia Thornton, Alberto Voltolini, and Simon Wimmer.
} 
- Huemer, M. 2007. 'Compassionate Phenomenal Conservatism.' Philosophy and Phenomenological Research 74: 30-55.

- Huemer, M. 2013. 'Phenomenal Conservatism.' Internet Encyclopedia of Philosophy.

- Kriegel, U. 2015a. 'Experiencing the Present.' Analysis 75: 407-413.

- Kriegel, U. 2015b. The Varieties of Consciousness. Oxford: OUP.

- McGrath, M. 2013. 'Phenomenal Conservatism and Cognitive Penetration: The Bad Basis Counterexamples.' In C. Tucker (ed.), Seemings and Justification. New York: OUP.

- Mitchell, J. 2020. 'The Attitudinal Opacity of Emotional Experience.' Philosophical Quarterly 70: 524-546.

- Peacocke, C. 1998. 'Conscious Attitudes, Attention, and Self-Knowledge.' In C. Wright, B.C. Smith, and C. Macdonald (eds.), Knowing Our Own Minds. Oxford: OUP.

- Perky, C.W. 'An Experimental Study of Imagination.' American Journal of Psychology 21: 422452.

- Pryor, J. 2000. 'The Skeptic and the Dogmatist.' Noûs 34: 517-549.

- Pryor, J. 2005. 'There is Immediate Justification.' In M. Steup and E. Sosa (eds.), Contemporary Debates in Epistemology. Malden MA: Blackwell.

- Recanati, F. 2007. Perspectival Thought. Oxford and New York: Oxford University Press.

- Sartre, J.-P. 1936. The Imagination. Trans. K.W. Williford and D. Rudrauf. London: Routledge, 2012.

- $\quad$ Sartre, J.-P. 1940. The Imaginary. Trans. J.M. Webber. London: Routledge, 2004.

- Siegel, S. and N. Silins 2015. 'The Epistemology of Perception.' In M. Matthen (ed.), Oxford Handbook of Philosophy of Perception. Oxford: OUP.

- Silins, N. 2011. 'Seeing through “the Veil of Perception”.' Mind 120: 329-367.

- Smithies, D. 2014. 'The Phenomenal Basis of Epistemic Justification.' In J. Kallestrup and M. Sprevak (eds.), New Waves in Philosophy of Mind. Basingstoke: Palgrave-MacMillan. 
- Teng, L. 2018. Is Phenomenal Force Sufficient for Immediate Justification.' Synthese 195: 637-656.

- Yablo, S. 1993. 'Is Conceivability a Guide to Possibility?' Philosophy and Phenomenological Research 53: 1-42. 